\title{
POWER LOSSES IN AUTOMOBILE TIRES
}

\author{
By W. L. Holt and P. L. Wormeley
}

ABSTRACT

This paper relates to the power loss or energy dissipated as heat in automobile tires when operated under different conditions of axle load, inflation pressure, speed, and tractive effort.

The special equipment used consists of two electrical absorption dynamometers, one operated as a motor and carrying on its shaft a wheel and the tire to be tested and the other operated as a generator and carrying on its shaft a smooth, flat-faced metal drum. The motor is mounted on a movable carriage, the arrangement being such that the tire can be forced against the drum with a pressure corresponding to the desired axle load. In this way the tire and drum constitute a friction drive by means of which the motor drives the generator. The field pole frame of each dynamometer is supported in ball bearings concentric with the armature shaft, and when in operation the magnetic drag or torque is measured on a scale. The power loss in the tire is the difference between the energy delivered by the motor to the tire and the energy delivered by the tire to the drum. This is determined from the speed of the motor and of the generator in conjunction with the torque on the respective field pole frames.

\section{OBJECT AND SCOPE OF THE INVESTIGATION}

The Bureau of Standards has undertaken a general investigation of automobile tires and inner tubes, and in connection with this work a rather comprehensive program has been laid out for dynamometer tests, to study among other things the power losses or energy dissipated as heat in tires operated under different conditions of axle load, inflation pressure, speed, temperature, and tractive effort. Preliminary tests have been made to determine the influence of these factors, which, aside from matters of design, are the principal items affecting the power loss in a tire. A continuation of the work will involve problems of design and construction, the influence of "over size" tires and of "cord tires" on power losses, mileage, and general efficiency of operation. An investigation will be made of inflation pressures as affecting the efficiency and economy of tire operation. Tests will be made to determine the effects of tire fillers, shields, puncture-proof tubes, etc., and the properties of cushion tires will be studied.

Tire dynamometers, although designed primarily for investigational work, are adapted for routine testing to determine the relative durability of tires and inner tubes. The surface of the 
drum (see Fig. 8) being smooth, there is little wear of the tread rubber, and the tire fails ultimately as a result of ply separation, which is the usual cause of failure in service, or a blow-out takes place at some weak spot which has developed during the test. It is necessary to determine the quality of the tread stock by physical tests and chemical analyses.

It has been suggested that a number of detailed requirements in the existing Government specifications be eliminated and that a laboratory service test be substituted therefor. In working out a plan such as this the results of dynamometer tests will be of great value in designing a standard tire-testing machine and in interpreting the results intelligently. In order to interpret the results of a dynamometer endurance test in terms of the probable mileage that a tire would give on the road, it will be necessary to make a large number of comparative tests under careful observation. The Bureau plans to conduct a series of such tests.

\section{EQUIPMENT}

The equipment (see Fig. 8) consists of two Sprague electrical absorption dynamometers having a capacity of 20 horsepower at 600 revolutions per minute and ro horsepower at 150 revolutions per minute. One dynamometer is operated as a motor carrying on its shaft a wheel and the tire to be tested. The other dynamometer is operated as a generator carrying on its shaft a smooth straight face iron drum 40 inches in diameter. The motor is mounted on a movable carriage, the arrangement being such that by the application of weights to a bell-crank lever the tire is forced against the drum with a pressure corresponding to the desired axle load. In this way the tire and drum constitute a friction drive by means of which the motor drives the generator. The field pole frame of each dynamometer is supported in ball bearings concentric with the armature shaft, and when in operation the magnetic drag or torque is measured on a Fairbanks beam scale. Each dynamometer is provided with a centrifugal tachometer which indicates the approximate speed in revolutions per minute and with a mechanical revolution counter operated by a magnetic clutch. The revolution counters are so designed that they may be read to the nearest one-tenth revolution of the tire or drum. The control panel is completely equipped for regulating the motor speed and generator load. Resistance grids are provided for absorbing the power generated. A switch is provided 
for operating simultaneously a stop watch and the revolution counters.

The inflation pressure is measured or changed while the tire is running, as follows: The tire valve, with the inside parts removed, is connected by a small tube to an attachment on the hub which communicates through a slip joint with a stationary chamber. This chamber is provided with a needle valve for closing the air passage leading from the tire, a standard tire valve for inflating or deflating the tire, and a connection for a tube leading to a pressure gage.

\section{METHOD OF DETERMINING POWER LOSS}

The distance from the center of the shaft to the knife-edge on each element is 15.756 inches, so that the power output of the motor and the power imput of the generator are computed by the formulas

$$
H P_{1}=\frac{T_{1} N_{1}}{4000}
$$

and, $H P_{2}=\frac{T_{2} N_{2}}{4000}$

Where $T_{1}=$ scale reading of motor element in pounds (corrected for windage),

$T_{2}=$ scale reading of generator element in pounds (corrected for windage),

$N_{1}=$ revolutions per minute of tire,

$N_{2}=$ revolutions per minute of drum.

The correction for windage of the wheel and tire is determined by noting the scale reading at various speeds with the tire out of contact with the drum. This is a minus correction. The correction for windage of the drum is determined by running the generator element as a motor and noting the scale reading at various speeds. This is a plus correction. The value of the windage corrections is very small. For example, the average corrections for a $33 \times 4$ tire run at 25 miles per hour, including both motor and generator, are equivalent to about 0.03 horsepower.

The power loss in a tire is given by the equation:

$$
H P_{1}-H P_{2}=\frac{T_{1} N_{1}-T_{2} N_{2}}{4000} \text { (horsepower) }
$$

This loss is due partly to deformation of the tire and partly to slip. The part due to deformation represents heat developed in the tire, and the part due to slip represents heat developed at 
the surface of contact between tire and drum. The loss due to deformation of the tire may be viewed as consisting of two parts: (I) That due to a radial force (axle load) and (2) that due to a tangential force (tractive effort). The loss resulting from axle load is indicated by rolling resistance, which is defined as the resistance to turning (measured at the drum surface) which the tire would offer if there were no tractive effort. An approximate value for this loss is obtained by substituting in equation (3) values of $T_{1}, T_{2}, N_{1}$, and $N_{2}$, observed when running the tire with no load on the generator.

When there is a tractive effort, the tangential component of the drum's reaction against the tire acts as a drag on the tread rubber. This tangential force has the double effect of compressing the tread rubber circumferentially just before it comes in contact with the drum and of producing a shearing action between the tread and carcass, with a corresponding circumferential or angular deformation of the carcass. This circumferential deformation of the tire produces creep in a manner similar to the creep of a belt on a pulley, since the material of the tire approaches the point of contact with the drum under compresssion and leaves it under tension. Portions of this surface of the tire are slipping on the drum, but it is probable that this slipping is confined to the ends of the surface of contact. The difference between the circumferential speed of the tire and drum is therefore more in the nature of a "creep" than what is ordinarily considered a "slip." If the tractive effort were increased sufficiently to produce "spinning" of the tire, the effect could more properly be called a "slip." The cushion forms an elastic bond between the tread and carcass and has its effect in producing creep, although this effect is not susceptible of measurement separately.

It is impossible to measure separately the losses due to creep and slip, but the sum of these losses may be approximated as follows: The pitch circle of the tire is defined as that circle which has the same linear velocity as that of the drum's surface when there is no tractive effort. We have therefore the relation-

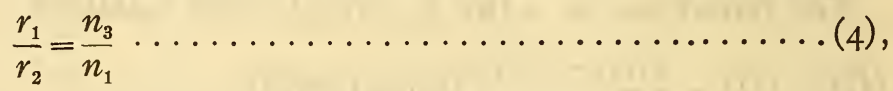

where $\quad r_{1}=$ pitch radius of tire in feet,

$r_{2}=$ radius of drum in feet,

$n_{1}=$ revolutions per minute of the tire,

$n_{3}=$ revolutions per minute of the drum. 
This equation is true, assuming that the slight tractive effort (about 2 pounds) which is introduced by friction in the generator is not appreciable.

If the observed speed of the drum is $n_{2}$ revolutions per minute when the tire is run under traction at a speed of $n_{1}$ revolutions per minute, we have

Creep and slip $=2 \pi \frac{\left(r_{1} n_{1}-r_{2} n_{2}\right)}{2 \pi r_{2}}$

$$
=n_{1} \frac{r_{1}}{r_{2}}-n_{2} \text { (revolutions per minute of the drum). (5). }
$$

The corresponding power loss due to creep and slip is

$$
H P_{3}=\frac{T_{2}}{4000}\left(n_{1} \frac{r_{1}}{r_{2}}-n_{2}\right) \text { horsepower }
$$

\section{RESULTS}

Fig. I shows the effect of tractive effort on the power loss at different inflation pressures. (This tractive effort is taken as the

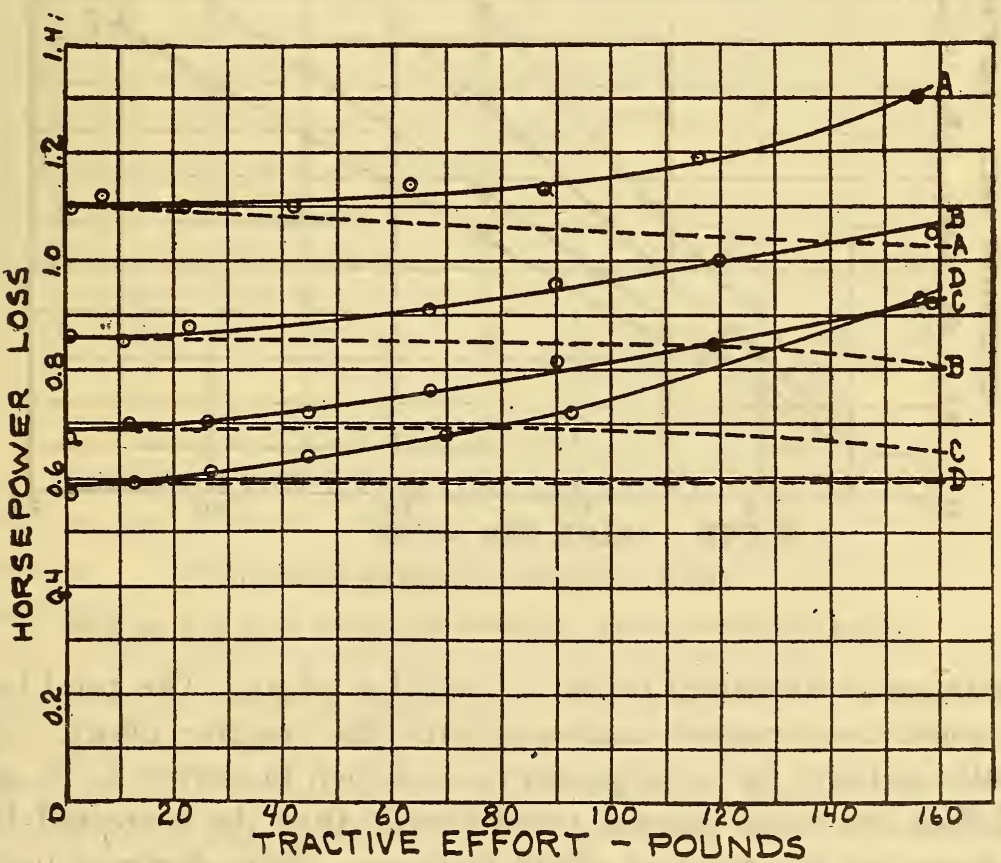

FIG. I.-Influence of tractive effort on power loss

${ }_{33} \mathrm{X}_{4}$ cord tire; speed, 25 mi. per hr.; axle load, 885 lbs.; air pressure in lbs./in. ${ }^{2}, \mathrm{~A}, 30 ; \mathrm{B}, 45 ; \mathrm{C}, 65 ; \mathrm{D}, 90$ resistance at the drum surface as calculated from the generator scale reading.) The total power loss as computed from equation (3) is shown in full lines. The dotted lines show the loss cor- 
rected for creep and slip as computed from equation (6). The sum of the creep and slip and the resulting power loss increase with the tractive effort, the rate of increase becoming greater as the tractive effort becomes greater.

It appears that for a well-inflated tire the loss corrected for creep and slip, as shown in curve $D$, is constant, that is, independent of the tractive effort and is equal to the loss due to rolling

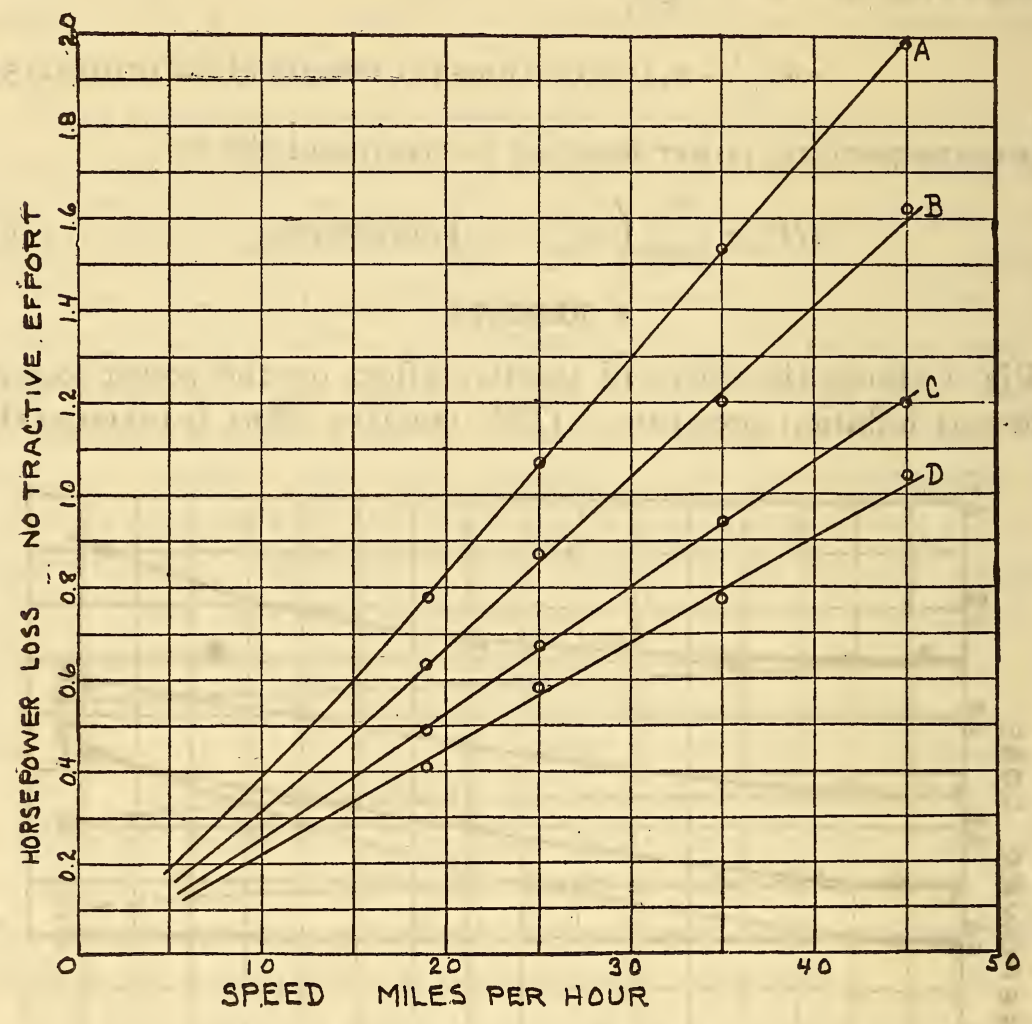

FIG. 2.-Influence of speed on power loss

$33 \times 4$ cord tire; axle load, 885 lbs.; air pressure in lbs./in. ${ }^{2}, A, 30 ; \mathrm{B}, 45 ; \mathrm{C}, 65 ; \mathrm{D}, 90$

resistance as measured under no tractive effort. The total loss, as would be expected, increases with the tractive effort. The results at lower inflation pressures as shown in curves $A, B$, and $\mathrm{C}$ follow the same general trend except that the corrected loss decreases as the tractive effort increases. This decrease under increased tractive effort results from a circumferential shearing deformation of the carcass (which is negligible under high inflation pressure), causing an appreciable increase of creep. Hence, the correction for creep and slip includes a part of the carcass loss. 
Fig. 2 shows the effect of speed on power loss at four different air pressures when a tire is run under constant axle load. The loss is nearly proportional to the speed, the rate of increase being greater as the air pressure decreases.

Fig. 3 shows the effect of axle load on power loss under four different air pressures when a tire is run at a constant speed. In this case also the loss is about proportional to the load, the rate of increase being greater as the air pressure decreases.

Fig. 4 shows the effect of inflation pressure on power loss under three different axle loads when a tire is run at constant speed.

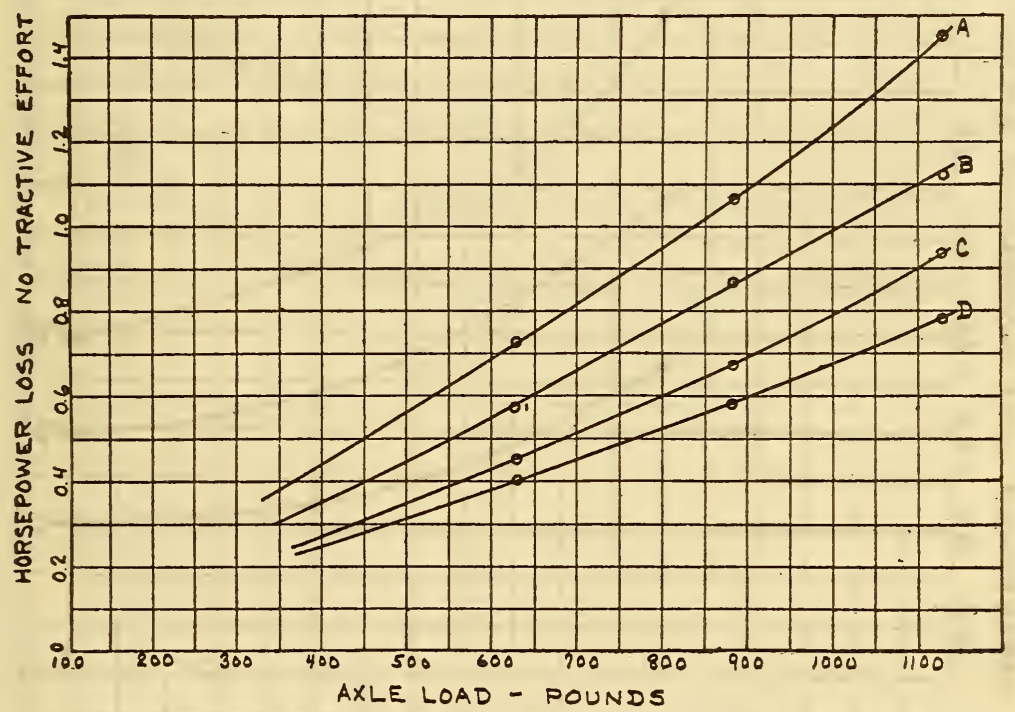

FIG. 3.-Influence of axle load on power loss

${ }_{33} \mathrm{X}_{4}$ cord tire; speed, $25 \mathrm{mi}$. per $\mathrm{hr}$.; air pressure in $\mathrm{lbs}$./in. ${ }^{2}, \mathrm{~A}, 30 ; \mathrm{B}, 45 ; \mathrm{C}, 65 ; \mathrm{D}, 90$

In these cases there is a rapid increase in power loss under low air pressures. Under high air pressures the loss approaches a constant value.

Fig. 5 shows the influence of temperature on power loss. Tires were started at room temperature in each case, in which condition the losses are comparatively high. The pressure was kept constant, and at the end of about 30 minutes tires had become warm and losses had decreased to a normal figure and remained constant.

Fig. 6 shows one of the results of the power loss, an increase in temperature and pressure in the tire. The curves showing temperature rise are based on the assumption that the volume of air in the tire remains constant, and that the capacity of the connecting tubes and the gauge are negligible. The initial temperature 
and pressure having been measured, the temperature at any time during the run is computed from the equation:

$$
t=T \frac{P_{2}}{P_{1}}-460
$$

where $t=$ temperature in tire in ${ }^{\circ} \mathrm{F}$,

$T=$ absolute temperature in tire at beginning of run,

$P_{1}=$ absolute pressure in tire at beginning of run,

$P_{2}=$ absolute pressure in tire corresponding to the temperature $t$.

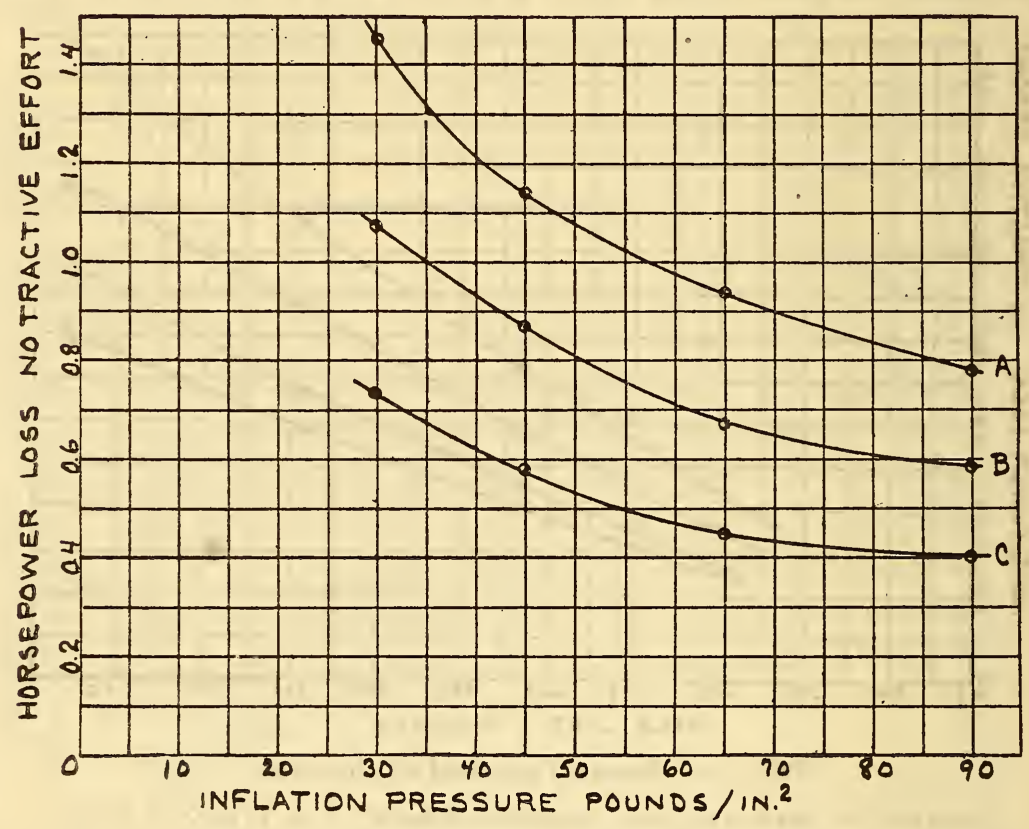

FIG. 4.-Influence of inflation pressure on power loss

$33 \times_{4}$ cord tire; speed, 25 mi. per hr.; axle load in lbs., A, Ir $30 ; \mathrm{B}, 885 ; \mathrm{C}, 625$

Fig. 7 is similar to Fig. 4, except that it shows a comparison of eight tires of different makes. The greater power loss in fabric tires shows up very plainly.

The question may arise as to the practical value of determining power losses in tires. These losses represent the energy absorbed by the tire and dissipated as heat while transmitting power from the axle to the road. They are due principally to internal strains in the tire, largely in the carcass. A large power loss results in (I) a correspondingly high fuel consumption, (2) quicker deterioration of the rubber and fabric on account of increased strains and increased temperature. 
As examples of the association of power loss with the life of tires, the loss in a 4 inch fabric tire is in the neighborhood of 40 per cent higher than in a cord tire, even where both are the same size. Based on the ordinary mileage guarantees, the life of a fabric tire is about 40 per cent less than that of a cord tire. A $35 \times 5$ cord tire was found in which the power loss was abnormally high. A subsequent examination of the tire showed that al-

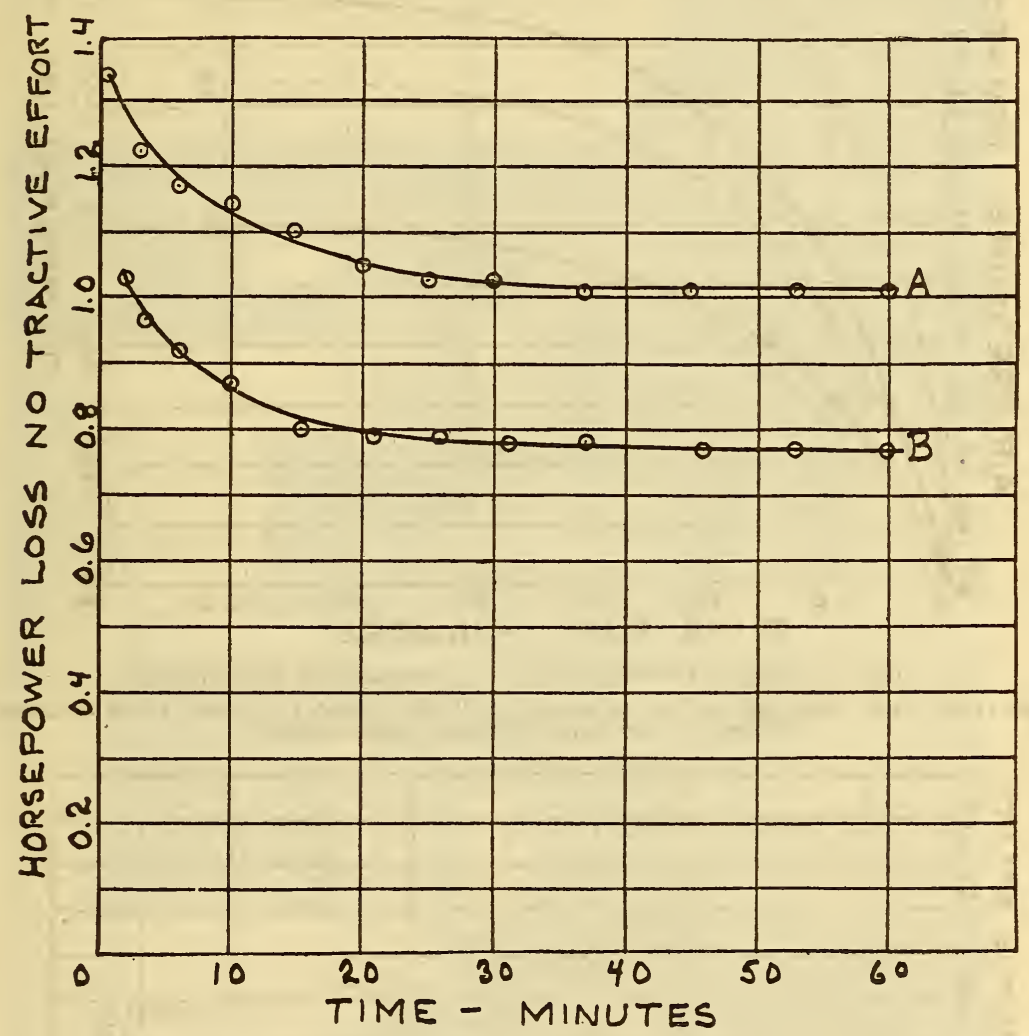

FIG. 5.-Influence of temperature on power loss

Speed, 25 mi. per hr.; axle load, 885 lbs.; air pressure, 60 lbs./in. ${ }^{2}$; tire A, $33 \times_{4}$ fabric; tire B, $33 \times_{4}$ cord though it was constructed in the usual way and with proper materials, the coats of rubber between the plies were very thin, a feature which would have resulted in a short life. Hence, the fact that the tire was not up to the proper standard was determined in the laboratory within a very short time without injury to the tire.

One point which should be recognized is that the power loss alone does not show the value of a tire from the standpoint of 


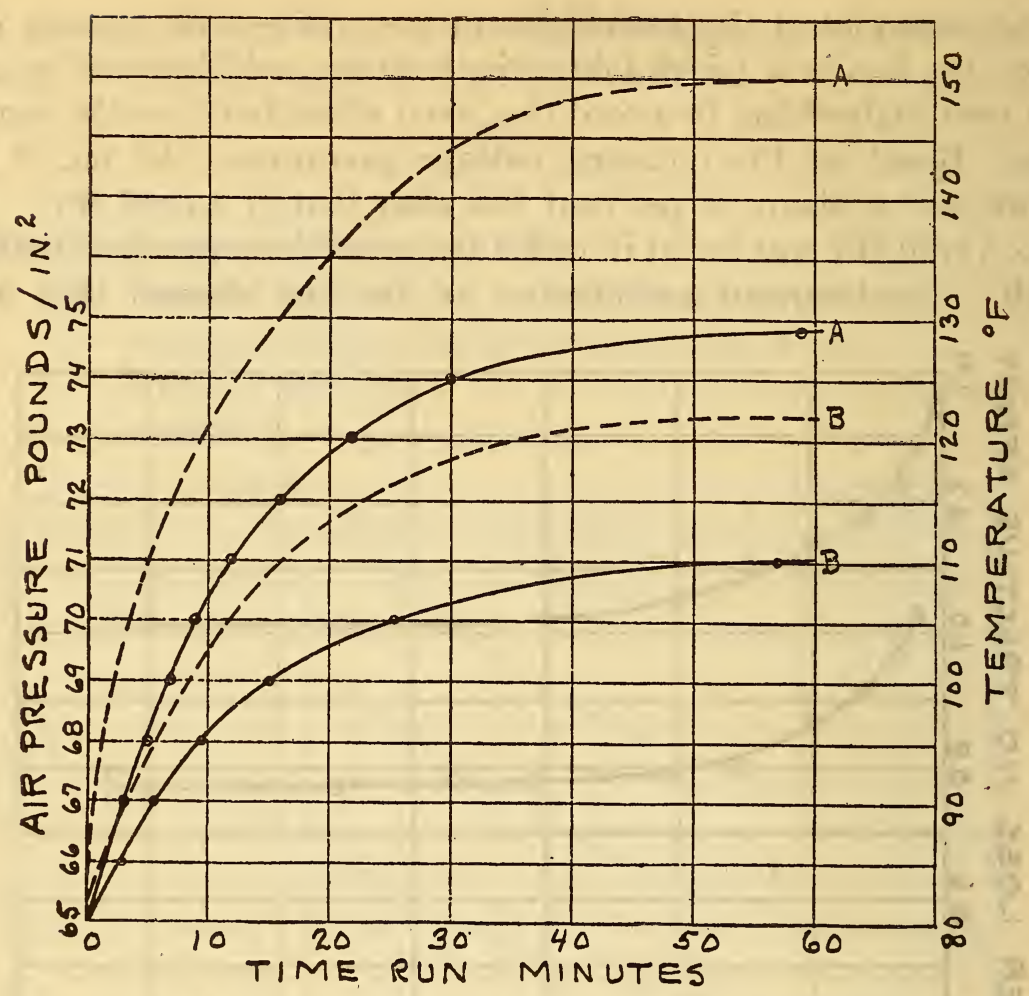

FIG. 6.-Rate of increase of inflation pressure and temperature

Speed, 25 mi. per hr.; axle load, 885 lbs.; air pressure, 65 lbs./in. ${ }^{2}$; tire A $_{33} \times_{4}$ fabric; tire B $33 \times_{4}$ cord; full lines, pressure rise; broken lines, temperature rise

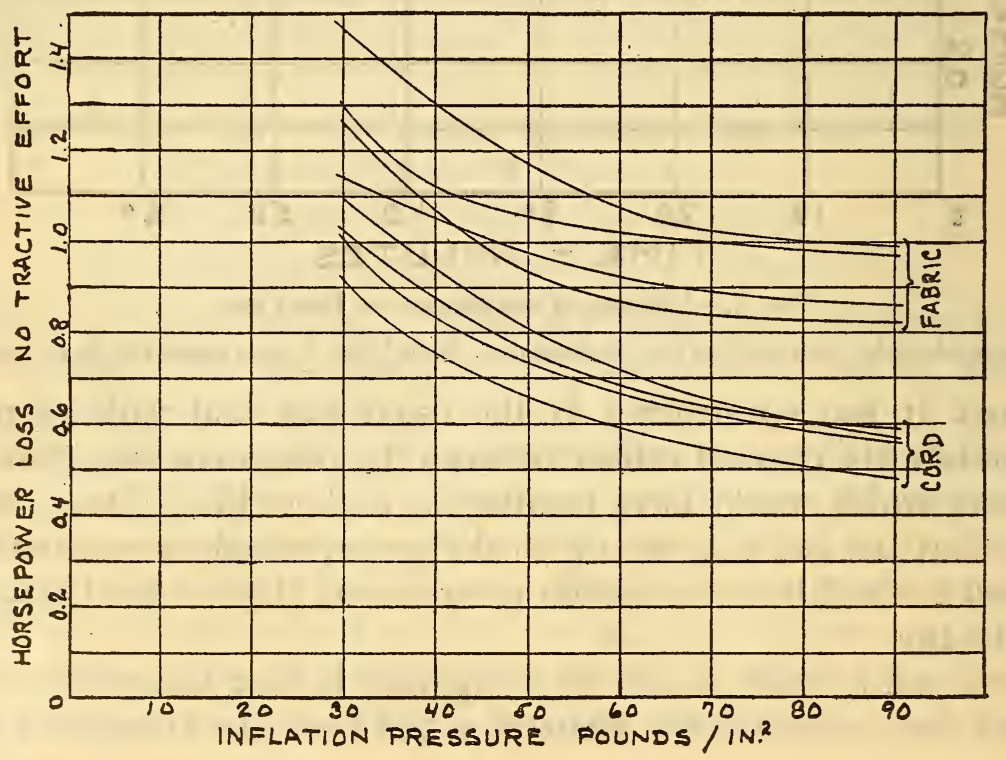

FIG. 7.-Comparison of tires

${ }_{43} \times_{4}$ cord tires, $4{ }_{33} \times_{4}$ fabric tires. Influence of inflation pressure on power loss; speed, $25 \mathrm{mi}$. per $\mathrm{hr}$. axle load, 885 lbs. 


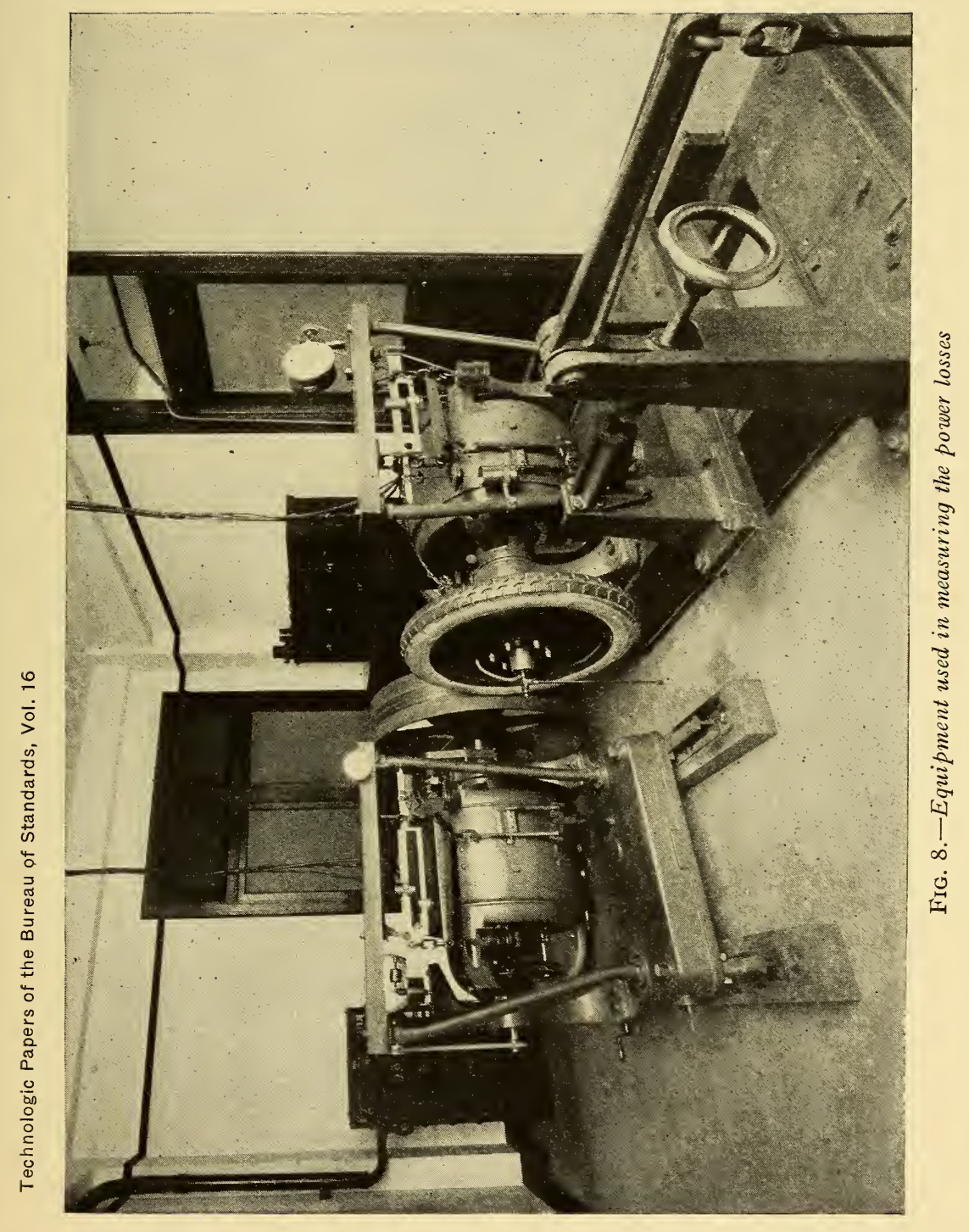



service, but, other things being equal, it should aid in determining the quality. For instance, the tire could be built with a reduced number of plies, which, with proper proportioning of rubber, might give a lower power loss. However, in service the tire would probably not be sufficiently rugged to withstand the ordinary blows to which a tire is subjected. A tire could be built of a very hard material, such as steel, which would result in a very small loss. The cushioning properties, however, would be entirely lacking. But, if we take two tires of the same general design, the one having the materials and construction so coordinated as to give a lowest power loss should have a longer life.

Aside from the question of design of tires, the power losses under different loads and air pressures indicate the proper conditions under which a tire should be run. In case of changes in these conditions the effect on the life of the tire is at least indicated by the corresponding change in power loss.

\section{CONCLUSIONS}

These preliminary results on power losses in tires show that, in general, the loss increases directly with an increase in speed or axle load and that it increases quite rapidly with decrease in air pressure below the standard. Tractive effort has a comparatively small effect on the power loss. There is a wide variation in the power loss in different tires run under the same conditions. Some makes of tires show a larger power loss than others, and fabric tires as a class show a considerable greater loss than cord tires. A continuation of this work in conjunction with a study of tire constructions and the action of tires under running conditions should give information which will help in developing better tire specifications and be an aid to the tire manufacturer.

Washington, December 3o, I92I. 



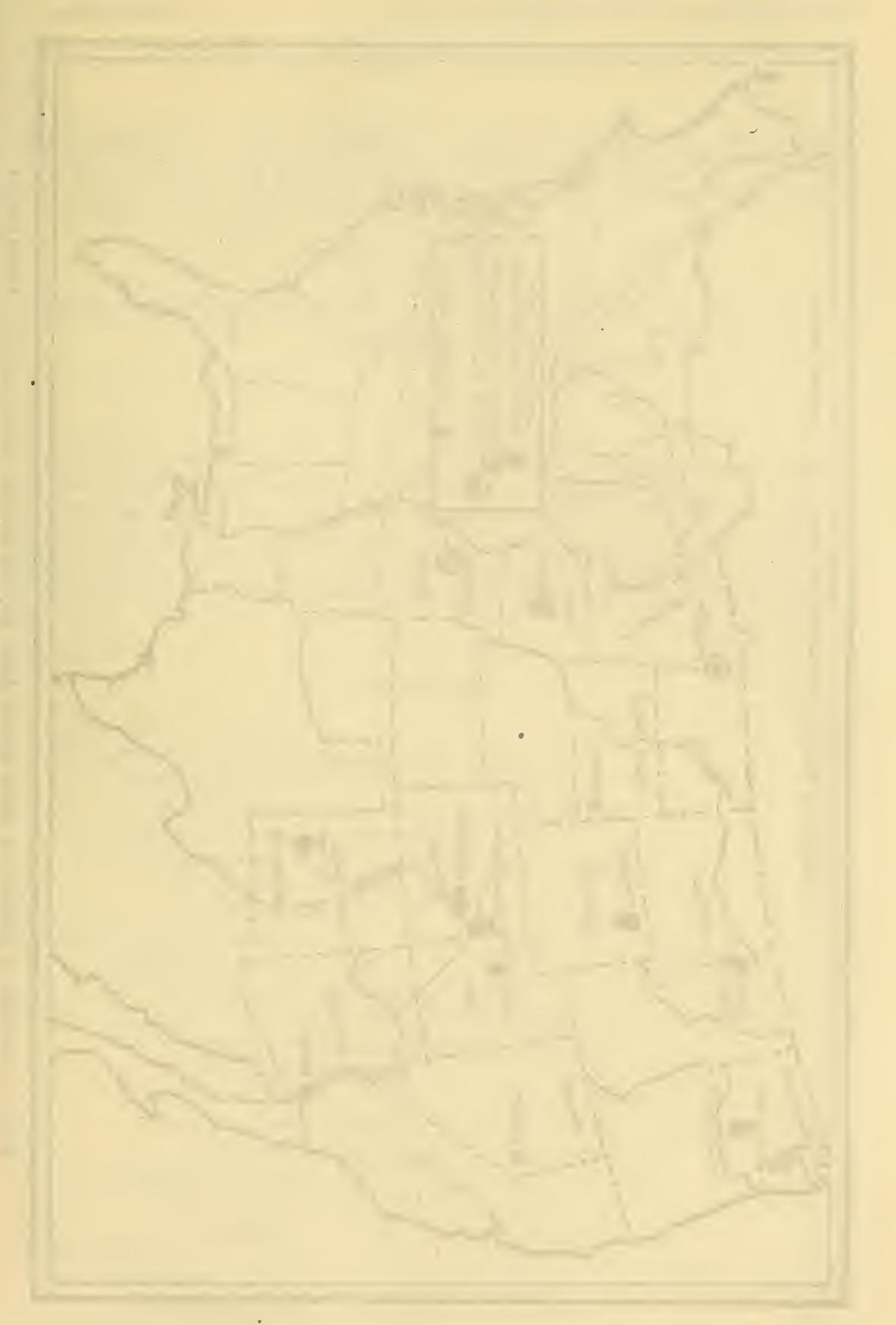




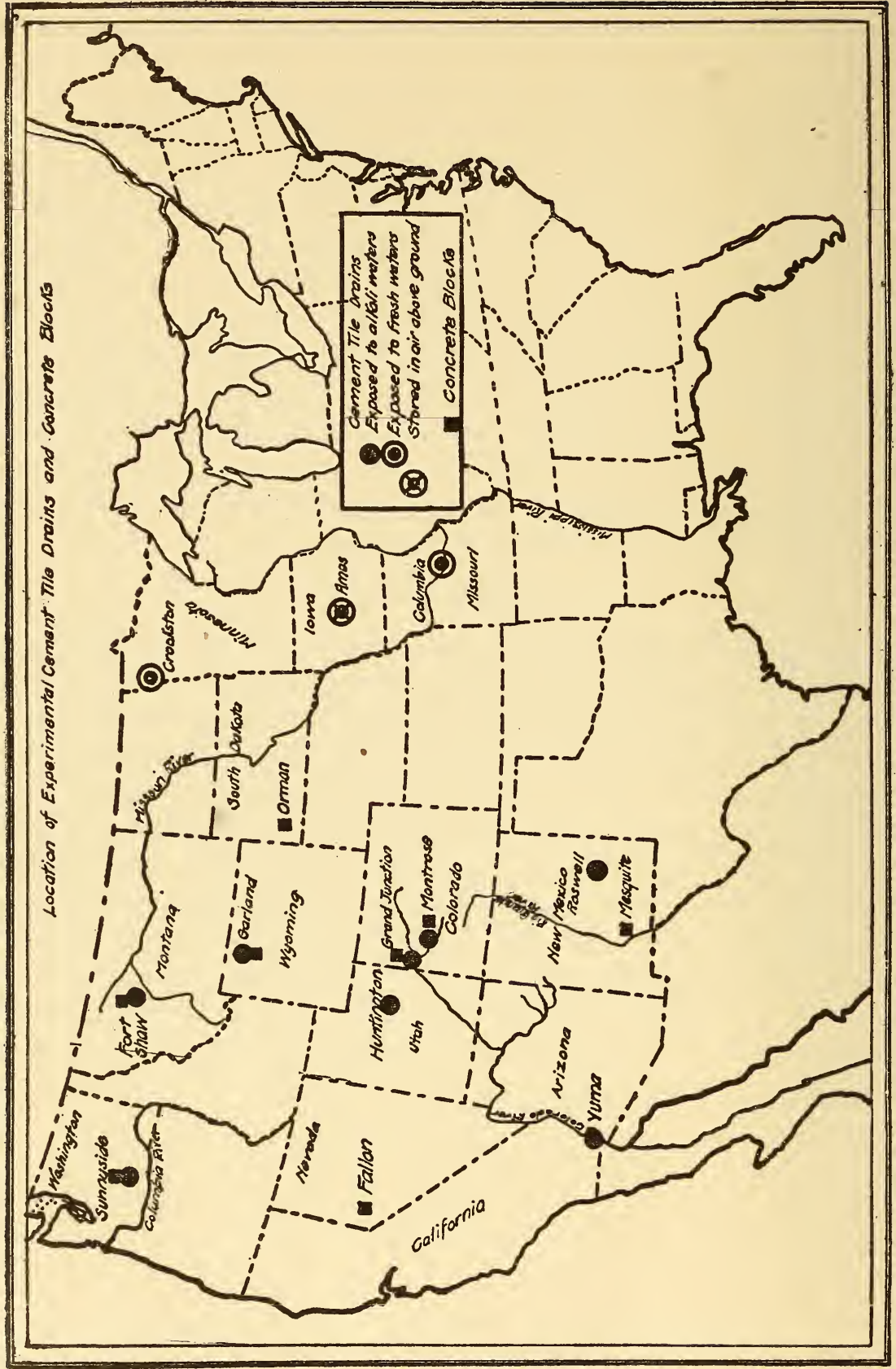

